\title{
DEVELOPMENT OF THE NEW PRODUCTION METHOD OF HEALTHFUL CRYOFROZEN NANOADDITIVES OF CHLOROPHYLL-CONTAINING VEGETABLES USING CRYOMECHANICAL PROCESSES
}

\author{
Viktoriya Pogarskaya \\ viktoria.pogarskaya@ukr.net \\ Raisa Pavlyuk ${ }^{1}$ \\ ktppom@ukr.net \\ Aleksey Pogarskiy ${ }^{l}$ \\ valve310@gmail.com \\ Ekaterina Dudnyk $\boldsymbol{k}^{1}$ \\ lacost05@ukr.net \\ Svitlana Loseva ${ }^{1}$ \\ ktppom@ukr.net \\ ${ }^{1}$ Department of Technology processing of fruits, vegetables and milk \\ Kharkiv State University of Food Technology and Trade \\ 333 Klochkivska str., Kharkiv, Ukraine, 61051
}

\begin{abstract}
The aim of the work is to develop the new production method of healthful cryofrozen nanoadditives of chlorophyll-containing vegetables $(\mathrm{CCV})$ in the nanosize form, using liquid and gas-like nitrogen with a high degree of chlorophyll preservation, without losses at defrost and without synthetic admixtures. The new method is based on using cryogenic "shock" freezing and low-temperature comminution as an innovation. Their joint use is accompanied by cryodestruction and cryomechanochemistry processes. The offered method gives a possibility not only to preserve chlorophylls, carotenoids and other BAS of initial raw materials, but also to transform hidden forms of BAS, bound with biopolymers, in free more completely.

Chlorophyll-containing vegetables were used as raw materials: spinach leaves, verdure of celery and parsley. There is offered and developed the new production method of healthful cryofrozen nanoadditives of CCV, allowing not only to preserve chlorophyll, $\beta$-carotene and other BAS of initial raw materials, but also to release their hidden, inactive forms more fully. The last ones are bound in fresh CCV in nanoassociates and nanopolymers. At getting cryofrozen additives, there takes extraction (or release) of BAS into the free nanoform, easily assimilated by the human organism. It is established, that fresh CCV contain 3.0...3.5 times more bound inactive chlorophyll, than free one.

It is established, that the use of the new method of processing CCV in cryofrozen additives at cryogenic "shock" freezing to temperature within a product $-35 \ldots-40{ }^{\circ} \mathrm{C}$ and fine-dispersed comminution result in the high degree of releasing hidden forms of chlorophylls and other BAS from vegetables. Their mass share is 2.5...3.5 times more than in fresh vegetables. At developing the new method of getting cryofrozen additives, the essential amount of hidden (bound) forms of chlorophylls and other BAS in CCV were discovered - hidden reserves of raw materials, unknown to the scientific community. It is established, that the storage term of obtained cryofrozen additives of CCV is 12 months, during which chlorophyll is fully preserved. At the same time it is demonstrated, that at defrost of additives with CCV, losses of chlorophyll and other BAS are not observed.

There are also studied enzymatic processes at CCV cryoprocessing, especially the activity of oxidizing enzymes (peroxidase and polyphenol oxidase) that influence a preservation degree of chlorophyll and other BAS. It is established, that at freezing CCV to $-18{ }^{\circ} \mathrm{C}$ in a product, inactivation of oxidizing enzymes doesn't take place. At that at further defrost of CCV, there takes place the increase of enzymatic activity in 1.4...1.5 times, comparing with fresh chlorophyll-containing vegetables. It is established, that at cryodestruction of $\mathrm{CCV}$ to $-35 \ldots-40{ }^{\circ} \mathrm{C}$ there takes place the complete inactivation of oxidizing enzymes, which activity is not renewed at defrosting a product.

The obtained cryofrozen additives with CCV in the nanosize form are a source of the unique complex of phytocomponents - chlorophyll, $\beta$-carotene, vitamin C, polyphenol compounds and other BAS and don't have analogues in the world.
\end{abstract}


Cryoadditives with CCV are five in one: BAS source, coloring agents, stiffeners, structure-formers and gel-formers. A green line of healthy products is developed, using cryoadditives of CCV: nanosorbets, nanobeverages, sponge cakes, sauces-dressings, cheese desserts and so on.

Keywords: cryomechanochemistry, cryogenic "shock" freezing, fine-dispersed comminution, chlorophyll-containing vegetables, chlorophyll, hidden forms of chlorophyll, healthful nanoproducts, cryoadditives.

\section{Introduction}

Chlorophyll-containing vegetables $(\mathrm{CCV})$ are promising raw materials for getting products and additives of the healthy direction $[1,2]$. CCV include: spinach, broccoli, Brussels sprout, green vetch, verdure of celery, dill, parsley and so on [3]. These CCV are a source of chlorophyll in the population's nutrition [1, 2]. A mass share of chlorophyll in them is from 0.1 to $0.8 \%[3,4]$. For today there is observed the deficit of natural green additives, including frozen and healthful products of $\mathrm{CCV}[3,4]$. It is promising to develop frozen chlorophyll-containing additives and products of CCV with a high content of chlorophyll for healthy nutrition.

According to last data of leading oncologists and vitaminologists of the USA, Japan, Netherlands, Sweden and other, there were proved antitumor, immunomodeling, detoxifying, antioxidant and antiradial properties of chlorophyll $[1,5]$. The established protective properties are explained by the chemical construction of its molecules. Their structure is approximated to one of human blood hemoglobin and is an unsaturated porphyrin ring [3,6].

Despite the unique healing properties of chlorophyll, CCV didn't find the proper use in the population's nutrition [6]. It is connected with the absence of information about healing properties of chlorophyll, recommended norms of its consumption and promotion of products of CCV. Mainly fresh chlorophyll-containing vegetables are used in food rations. It is connected with the fact that there are objective difficulties at CCV processing in food products, because of the fact that chlorophylls a and $\mathrm{b}$ are unstable compounds, fast destructed at processing; they lose their color or acquire the brown one and lose their properties $[3,6]$. It is demonstrated, that chlorophyll losses at CCV processing under the thermal effect are from 20 to $100 \%$, at freezing - up to $35 \%$ and at defrost near $50 \%$ more [7-9].

One of most progressive methods for processing and preserving products of vegetable and animal origin is "shock" freezing [3,9], based on using cryogenic liquids as cooling agents. At that liquid nitrogen, carbonic acid and other are used as cryoagents.

The analysis of literary data demonstrated that the problem of preservation and stabilization of chlorophyll and other BAS at processing CCV in ready products, including freezing, is not almost solved in the international practice [9-11]. Its solution needs new non-standard approaches, ideas, innovations.

A variant of solving the problem of preservation and stabilization of chlorophyll and other BAS at CCV processing in frozen fine-dispersed additives and products is the use of the method of deep processing of raw materials as an innovation, based on the complex effect of cryogenic "shock" freezing and fine-dispersed comminution on raw materials [10, 11]. The use of this method of deep processing provides the highest degree of preserving vitamins and other BAS [12, 13]. A shortcoming of the cryogenic freezing method is essential losses of vitamins and other BAS (up to $50 \%)$ at defrost after storing a frozen product during 6 months $[14,15]$. At that there are observed losses of cellular juice at defrost that are up to $10 \%[16,17]$.

Exclusions are results of fundamental and applied studies of the influence of the complex effect of cryogenic "shock" freezing and fine-dispersed comminution of fruits, vegetables, mushrooms, obtained at the Kharkiv state university of food and trade [10-12]. Especially, there are developed cryogenic nanotechnologies of frozen fruits and vegetables and fine-dispersed pastelike additives of fruits [18-20], fine-dispersed cryopastes of carotene-containing vegetables and berries [17], girasol [20], mushrooms [18], spicy vegetables and natural spices [21]. The developed cryogenic technologies allowed to discover in products, obtained of fruits and vegetables, hidden 
forms of BAS, which mass share is 2.0..3.5 times more than in initial vegetable raw materials [10, $11,18]$. Just this approach is used in the work.

The conducted analysis of literary data testifies that the question, why at getting frozen products of $\mathrm{CCV}$ and at further defrost essential losses of chlorophyll and other BAS take place still unsolved for today. Losses are: $25 . .35 \%$ - At "shock" freezing of CCV, 50...60 \% - at defrost of a product $[3,8,19]$. A cryogenic method and technologies of cryofrozen additives of CCV that give a possibility to preserve chlorophylls and other BAS at freezing, storage and further defrost of a product are not developed. It needs additional studies.

The aim of the work is to develop the new production method of healthful cryofrozen nanoadditives of chlorophyll-containing vegetables using cryomechanochemistry processes. The new method is based on freezing with using liquid and gas-like nitrogen and fine-dispersed comminution that allow to get cryoadditives of $\mathrm{CCV}$ in the nanosize form, differ by the high degree of chlorophyll preservation at cryofreezing, storage and defrost.

\section{Materials and Methods}

Spinach leaves, celery and parsley verdure are used as raw materials at developing the new method of producing cryofrozen additives as pastes of chlorophyll-containing vegetables (Fig. 1). Regularities of the influence of cryoprocessing and fine-dispersed comminution on the transformation of $\beta$-carotene, L-ascorbic acid, phenol compounds and also enzymatic activity, obtained at the experiments, don't depend on CVV variety.

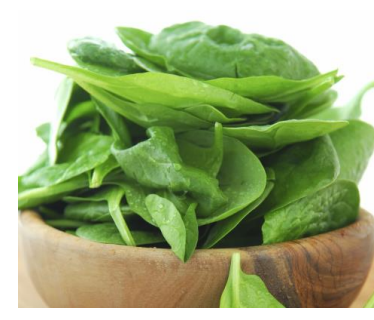

$a$

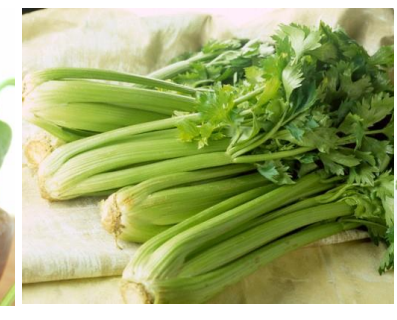

$b$

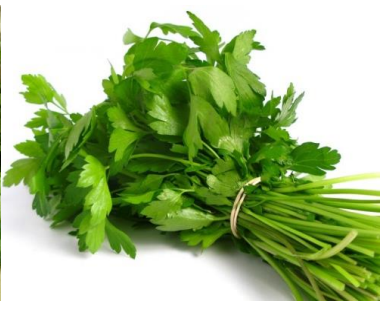

Fig. 1. Raw materials for the research: fresh carotene-containing vegetables: $a$ - spinach leaves, $b$ - celery verdure, $c$ - parsley verdure

The scientific studies were conducted in the Kharkiv state university of food and trade (KSUFT, Ukraine) at the department of processing technologies of fruits, vegetables and milk. The experimental studies were conducted on the base of the research laboratory of "Innovative cryoand nanotechnologies of vegetable additives and healthful products" of this department.

The model studies at getting cryoadditives of CCV were conducted with using cryogenic "shock" freezing in the fast freezing experimental apparatus, using liquid and gas-like nitrogen as a cooling agent and inert medium. The apparatus is designed for freezing products with a hard tunic and liquid ones, put in the special package [3]. The gas medium temperature in the freezing chamber is set by hand and automatically kept constant during the experiment. At conducting the model studies temperature $-60{ }^{\circ} \mathrm{C}$ in the working chamber was chosen optimal. $\mathrm{CCV}$ were frozen with the high speed from 0.5 to $10{ }^{\circ} \mathrm{C}$ per minute to final temperatures within the product $-18 \ldots-40{ }^{\circ} \mathrm{C}$.

For fine-dispersed comminution of chlorophyll-containing vegetables there was used the homogenizer-comminutor Robot Couper (France) and low-temperature comminutor PacoJet (France) [3].

\section{1. Experimental procedures}

The quality by BAS contents was determined in fresh and cryofrozen chlorophyll-containing vegetables (spinach leaves, celery and parsley verdure) and also cryofrozen fine-dispersed puree of them, especially:

- chlorophylls a and b, by the spectrophotometric method by determining the optic density of acetone tinctures of the experimental samples; 
- L-ascorbic acid, by the method of visual and potentiometric titration by the solution of 2,6-diclorophenolindophenol $\mathrm{Na}$;

- $\beta$-carotene, by the colorimetric method of Muri after extracting carotene of a product by an organic solvent and its cleaning from concomitant coloring substances, using column chromatography;

- polyphenol compounds, by the titrometric method, based on the property of phenol compounds to oxidize at presence of an indigo carmine indicator, the calculation of tanning substances was realized by tannin; bic acid.

- oxidizing enzymes, by the method, based on the property of kinones to oxidize ascor-

The content of dry substances, organoleptic parameters, general sugar and pectin in taken average samples of the initial raw materials, developed cryoadditives of CCV and healthful products with their use was determined according to existent SS. Especially, the quality of the fresh chlorophyll-containing vegetables (spinach leaves, celery and parsley verdure) was controlled according to SSU 8061-2015 «Spinach» (Technical conditions), SSU 6010-2008 «Fresh parsley» (Technical conditions), SSU «Fresh celery» Technical conditions. The quality of frozen CCV was controlled according to SS "Fast-frozen fruits and vegetables" (General technical conditions), "Fast-frozen vegetables and vegetable mixtures" TCU 153-2559300973-02-2013 and other. The experimental results were processed, using mathematical methods and computer technologies.

\section{Results}

There was developed the new production method of healthful cryofrozen nanoadditives. It is based on cryomechanochemistry processes at cryogenic "shock" freezing of CCV and dine-dispersed comminution. At its developing there has been established the existence of the essential amount of hidden (bound) forms of chlorophyll and other BAS in CCV - hidden reserves of the raw materials. It is established, that at cryofreezing of $\mathrm{CCV}$ to $-35 \ldots-40{ }^{\circ} \mathrm{C}$ the complete inactivation of oxidizing enzymes, which activity is not renewed at comminution and further defrost, takes place. It is demonstrated, that the use of the developed method results in the high release degree of hidden forms of chlorophyll and other BAS at CCV processing in nanoadditives. Comparing with fresh vegetables, the mass share of BAS in obtained frozen nanoadditives is 2.5..3.5 times more. It is demonstrated, that at defrost of additives with $\mathrm{CCV}$, losses of chlorophyll and other BAS are not observed. Their storage term is established as 12 months.

The obtained cryofrozen additives of CCV are in the nanosize form, are a source of the unique complex of phytocomponents - BAS and structure-forming substances. The green line of healthy products is developed, using cryoadditives of CCV: nanosorbets, nanobeverages, sponge cakes, sauces-dressings, cheese desserts and so on (Fig. 2, 3). The new products can be produced at both big food enterprises and at restaurant economy ones.

At producing healthful products, cryoadditives with CCV were used as five in one. At first, as improvers by BAS (chlorophyll, carotene, L-ascorbic acid, phenol compounds) and by prebiotic substances (soluble pectin, cellulose, protein). At the same time green cryoadditives function as coloring agents, stiffeners, structure-formers and gel-formers (Fig. 2, 3). It gives a possibility to exclude the use of artificial food admixtures at producing the green line of healthful products.

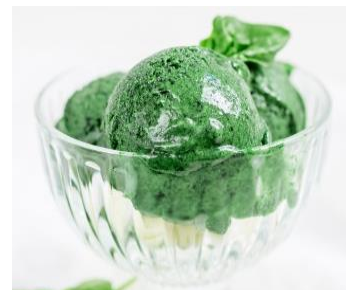

$a$

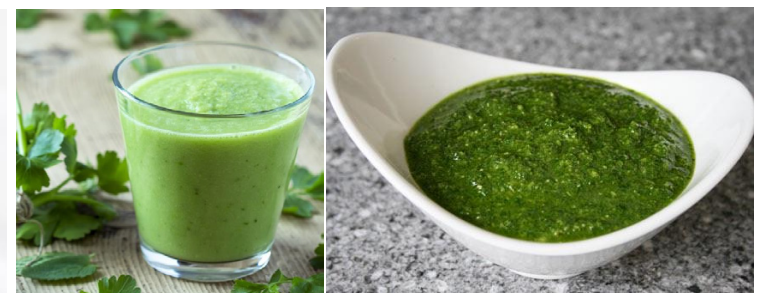

$b$

c

Fig. 2. Green line of healthy products, obtained using cryoadditives of chlorophyll-containing vegetables: $a$ - nanosorbets, $b$ - nanobeverages, $c$ - sauces-dressings 


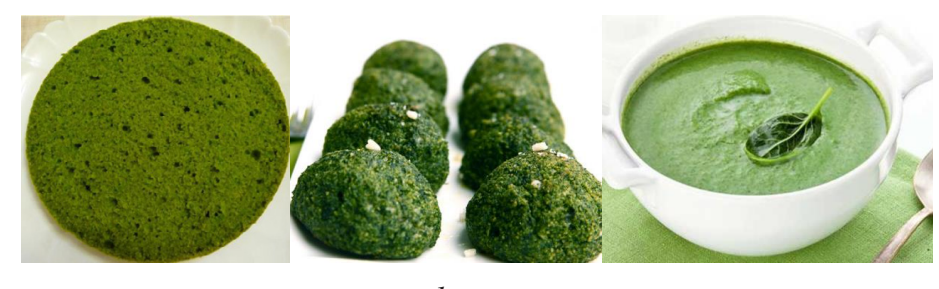

$a$

$b$

Fig. 3. Green line of healthy products, obtained using cryoadditives of chlorophyll-containing vegetables: $a$-sponge cakes, $b$ - cheese desserts, $c$ - soups-puree

The developed method and technology of cryofrozen nanoadditives of crlorophyll-containing vegetables were probated under production conditions of RPE “Crias Plus” (Ukraine, Kharkiv), RPF «FIPAR» (Ukraine, Kharkiv), normative documents were elaborated (TC, TI, TTC).

\section{Conclusions}

There is offered and developed the new production method of healthful cryofrozen nanoadditives of chlorophyll-containing vegetables, using liquid or gas-lie nitrogen with the high preservation degree of chlorophyll and other BAS, without losses at defrost and without using synthetic admixtures. The new method includes cryogenic "shock" freezing and fine-dispersed comminution, accompanied by cryodestruction and cryomechanochemistry processes, as an innovation.

It is established, that the new production method of cryofrozen nanoadditives of CCV allows not only to preserve chlorophyll, $\beta$-carotene and other BAS of initial raw materials completely, but also to release their hidden, inactive forms more fully. The last ones are bound in fresh chlorophyll-containing vegetables in nanoassociates and nanopolymers. At getting cryofrozen additives, there takes extraction (or release) of BAS into the free nanoform, easily assimilated by the human organism. It is established, that fresh CCV contain 3.0..3.5 times more bound inactive chlorophyll, than free one. The mechanism of increase is explained.

It is also demonstrated, that enzymatic processes at CCV cryoprocessing, especially the activity of oxidizing enzymes (peroxidase and polyphenol oxidase) influence a preservation degree of chlorophyll and other BAS. It is established, that at freezing CCV to $-18{ }^{\circ} \mathrm{C}$ in a product, inactivation of oxidizing enzymes doesn't take place. At that at further defrost of $\mathrm{CCV}$, there takes place the increase of enzymatic activity in 1.4...1.5 times, comparing with fresh chlorophyll-containing vegetables. It is established, that at cryodestruction of $\mathrm{CCV}$ to $-35 \ldots-40{ }^{\circ} \mathrm{C}$ there takes place the complete inactivation of oxidizing enzymes, which activity is not renewed at defrosting a product;

It is demonstrated, that the obtained cryofrozen additives with CCV in the nanosize form are a source of the unique complex of phytocomponents - chlorophyll, $\beta$-carotene, vitamin $C$, polyphenol compounds and other BAS and don't have analogues in the world. Cryoadditives with CCV are five in one: BAS source, coloring agents, stiffeners, structure-formers and gel-formers. The green line of healthy products is developed, using cryoadditives of CCV: nanosorbets, nanobeverages, sponge cakes, sauces-dressings, cheese desserts and so on.

The green line of healthy products can be produced at both big food enterprises and at restaurant economy ones.

\section{References}

[1] Wu, Z.-M., Wang, L., Zhu, W., Gao, Y.-H., Wu, H.-M., Wang, M. et. al. (2017). Preparation of a chlorophyll derivative and investigation of its photodynamic activities against cholangiocarcinoma. Biomedicine \& Pharmacotherapy, 92, $285-292$. doi: https://doi.org/10.1016/j.biopha.2017.05.052

[2] Burana-osot, J., Soonthornchareonnon, N., Hosoyama, S., Linhardt, R. J., Toida, T. (2010). Partial depolymerization of pectin by a photochemical reaction. Carbohydrate Research, 345 (9), 1205-1210. doi: https://doi.org/10.1016/j.carres.2010.04.007

[3] Pavliuk, R. Yu. et. al. (2019). Nanotekhnolohiyi «NaturSuperFood» dlia zdorovoho kharchuvannia. Kharkiv: Fakt, 487.

[4] Hlorofill. Available at: https:/edaplus.info/food-components/chlorophyll.html

[5] Özkan, G., Ersus Bilek, S. (2015). Enzyme-assisted extraction of stabilized chlorophyll from spinach. Food Chemistry, 176, 152-157. doi: https://doi.org/10.1016/j.foodchem.2014.12.059 
[6] Pavlyuk, R. Yu. (Ed.) (2017). Entsiklopediya pitaniya. Vol. 5. Biologicheski aktivnye dobavki. Kharkiv: Mir Knig, 406.

[7] Limantara, L., Dettling, M., Indrawati, R., Indriatmoko, Brotosudarmo, T. H. P. (2015). Analysis on the Chlorophyll Content of Commercial Green Leafy Vegetables. Procedia Chemistry, 14, 225-231. doi: https://doi.org/10.1016/j.proche.2015.03.032

[8] Sinha, N. K., H’yu, I. G. (2014). Nastol'naya kniga po pererabotke plodoovoshchnoy produktsii. Sankt-Peterburg: Professiya, 912.

[9] Evans, Dzh. A. (2010). Zamorozhennye pishchevye produkty. Sankt-Peterburg: Professiya, 448.

[10] Pavlyuk, R., Pogarskaya, V., Cherevko, O., Pavliuk, V., Radchenko, L., Dudnyk, E. et. al. (2018). Studying the complex of biologically active substances in spicy vegetables and designing the nanotechnologies for cryosupplements and nanoproducts with health benefits. Eastern-European Journal of Enterprise Technologies, 4 (11 (94)), 6-14. doi: https://doi.org/10.15587/17294061.2018.133819

[11] Pavlyuk, R., Pogarska, V., Timofeyeva, N., Bilenko, L., Stukonozhenko, T. (2016). Exploring the processes of cryomechanodestruction and mechanochemistry when devising nano-technologies for the frozen carotenoid plant supplements. Eastern-European Journal of Enterprise Technologies, 6 (11 (84)), 39-46. doi: https://doi.org/10.15587/1729-4061.2016.86968

[12] Pavlyuk, R., Pogarska, V., Kakadii, I., Pogarskiy, A., Stukonozhenko, T. (2017). Influence of the processes of steam-thermal cryogenic treatment and mechanolysis on biopolymers and biologically active substances in the course of obtaining health promoting nanoproducts. Eastern-European Journal of Enterprise Technologies, 6 (11 (90)), 41-47. doi: https://doi.org/ 10.15587/1729-4061.2017.117654

[13] Evans, J. (2016). Emerging Refrigeration and Freezing Technologies for Food Preservation. Innovation and Future Trends in Food Manufacturing and Supply Chain Technologies, 175-201. doi: https://doi.org/10.1016/b978-1-78242-447-5.00007-1

[14] Tuan Pham, Q. (2014). Freezing time formulas for foods with low moisture content, low freezing point and for cryogenic freezing. Journal of Food Engineering, 127, 85-92. doi: https://doi.org/10.1016/j.jfoodeng.2013.12.007

[15] James, S. J., James, C. (2014). Chilling and Freezing. Food Safety Management, 481-510. doi: https://oi.org/10.1016/b978-012-381504-0.00020-2

[16] Tu, J., Zhang, M., Xu, B., Liu, H. (2015). Effects of different freezing methods on the quality and microstructure of lotus (Nelumbo nucifera) root. International Journal of Refrigeration, 52, 59-65. doi: https://doi.org/10.1016/j.ijrefrig.2014.12.015

[17] Min, K., Chen, K., Arora, R. (2014). Effect of short-term versus prolonged freezing on freeze-thaw injury and post-thaw recovery in spinach: Importance in laboratory freeze-thaw protocols. Environmental and Experimental Botany, 106, $124-131$. doi: https://doi.org/10.1016/j.envexpbot.2014.01.009

[18] Pavlyuk, R., Pogarska, V., Matsipura, T., Maximova, N. (2015). Development of nanotechnology of fine frozen champignon puree (agaricus bisporus). Eastern-European Journal of Enterprise Technologies, 6 (10 (78)), 24-28. doi: https://doi.org/ 10.15587/1729-4061.2015.56145

[19] Pavluk, R., Pogarskiy, A., Kaplun, H., Loseva, S. (2015). Developing the cryogenic freezing technology of chlorophyll-containing vegetables. Eastern-European Journal of Enterprise Technologies, 6 (10 (78)), 42-47. doi: https://doi.org/10.15587/17294061.2015.56111

[20] Pavlyuk, R., Pogarska, V., Balabai, K., Pavlyuk, V., Kotuyk, T. (2016). The effect of cryomechanodestruction on activation of heteropolysaccaride-protein nanocomplexes when developing nanotechnologies of plant supplements. Eastern-European Journal of Enterprise Technologies, 4 (11 (82)), 20-28. doi: https://doi.org/10.15587/1729-4061.2016.76107

[21] Pavlyuk, R., Pogarskaya, V., Radchenko, L., Yurieva, O., Gasanova, A., Abramova, A., Kolomiets, T. (2015). The development of technology of nanoextracts and nanopowders from herbal spices for healthful products. Eastern-European Journal of Enterprise Technologies, 3 (10 (75)), 54-59. doi: https://doi.org/10.15587/1729-4061.2015.43323 